\title{
What to Do When Everyone Wants You to Collaborate: Managing the Demand for Library Support in Systematic Review Searching ${ }^{1}$
}

\author{
Sandy Campbell and Marlene Dorgan
}

\begin{abstract}
The demand for systematic review support in academic health sciences libraries is increasing. To manage the demand, the John W. Scott Health Sciences Library at the University of Alberta has created an action plan consisting of eight strategies. The results of implementing these strategies have been varied. Some have shown immediate results, while others are long term strategies.
\end{abstract}

\section{Introduction}

While systematic reviews date back to 1904 [1], their production began to increase significantly in the 1990s reaching more than 5000 per year in 2007 [2]. Systematic reviews became a standard research method for the production of high-quality, synthesized evidence for clinical practice, and Cochrane Reviews "... are internationally recognized as the highest standard in evidencebased health care" [3]. The number of Cochrane Reviews produced over time also shows a constant increase [4]. The John W. Scott Health Sciences Library (Scott Library) at the University of Alberta has experienced a strong and consistently increasing demand for systematic review consultation services by librarians. At the same time, budget restraints do not allow for increased staff to meet the demand. The Scott Library is proactively managing the demand and improving service efficiency so that researchers' needs are met within the Library's resources.

The role of librarians and the value of their skill set in systematic review searching has been well-described in the literature $[1,5-8]$, but this literature offers no advice on how to cope with overwhelming demand. To some extent the demand is driven by external forces. The Cochrane Handbook for Systematic Reviews of Interventions recommends that reviewers consult librarians for their searches [9]. Standards for Systematic Reviews produced by the Institute of Medicine of the National Academies of Sciences in 2011 require that reviewers "work with a librarian or other information specialist trained in performing systematic reviews to plan the search strategy" [10]. Further, to strengthen the evidence that is being synthesized, some funding agencies such as the Canadian
Institutes of Health Research strongly recommend that expert searchers, usually librarians, execute the searches that underpin systematic reviews and co-author the publication [11]. Systematic reviews, requiring librarian support, are also commonly used as the form of literature review for theses and dissertations in health sciences subjects. A recent preliminary study by Cobus-Kuo, Gore, and Kloda [12] revealed that between 1981 and 2012, 314 theses and dissertations produced at 10 Canadian universities contained systematic reviews or research syntheses. The University of Alberta had the highest number of theses and dissertations (67) containing systematic reviews and research syntheses [12]. As a result of all of these factors, academic health sciences librarians are facing exponential increases in demand for their time. In the Scott Library the number of all librarian consultations, including systematic review consultations, rose from 210 in 2010 to 633 in the 12 months from September 2013 to August 2014.

\section{Description}

As part of a broader strategic planning process, the Scott Library developed a plan of eight strategies to manage the increased demand for librarian consultations.

Strategy 1: Freeing librarians' time by ensuring that all work is appropriately assigned to academic and nonacademic staff

Librarians were removed from general reference desk service and most of their reference work was consultations. Senior nonacademic staff members provided reference desk service and did much of the basic instruction, which can be scripted.

Sandy Campbell ${ }^{2}$ and Marlene Dorgan. John W. Scott Health Sciences Library, University of Alberta Edmonton, 116 St. and 85 Ave,

Edmonton, AB T6G 2R3.

${ }^{1}$ This article has been peer reviewed.

${ }^{2}$ Corresponding author: (email: scampbel@ualberta.ca) 


\section{Strategy 2: Building searcher capacity in the librarian} community

Systematic reviews are now being conducted in subjects outside of health sciences and outside of academic libraries [13]. To encourage colleagues to meet the demand in their own subject libraries, local librarians were invited to attend a regularly scheduled class on systematic review searching. The class was also offered as a workshop for the Northern Alberta Health Libraries Association. Further, a module on systematic review searching was included in a Health Sciences Librarianship course offered through the University of Alberta graduate School of Library and Information Studies (SLIS) [14], and a one-credit weekend course in systematic review searching was offered through SLIS. Scott Librarians also take part in informal and formal peer mentoring projects [15] as opportunities arise.

\section{Strategy 3: Lobbying for additional librarian and expert searcher positions}

The Library has had success in the past in developing shared librarian positions with local research organizations. Currently four positions exist in which a librarian, who is an expert searcher, is employed $80 \%$ of the time with a health research group and $20 \%$ with the Scott Library. These arrangements are designed to be sufficiently flexible so that the librarians can vary their schedules to meet demand for search consultations. The Library also encourages applicants for large research grants to incorporate research librarian positions into their project budgets. Finally, the Library encourages external organizations that conduct systematic reviews to create or maintain librarian and expert searcher positions.

\section{Strategy 4: Redefining service policies for external users}

Historically, the Scott Library offered fee-based services to the general public. The Scott Library now offers their extended reference service solely to members of the faculty, staff, and students of the University of Alberta.

\section{Strategy 5: Better organizing search support resources}

Due to the strengths of specialties in areas such as pediatrics, cardiac care, diabetes, obesity, and public health in the Edmonton health research community, many studies are undertaken in closely related areas and searches are often repetitious. To streamline these searches, librarians now post filters or hedges to both the Expert Searches section of the OVID platform and a Health Sciences Search Filters webpage (http://guides.library.ualberta.ca/ content.php?pid $=448005 \&$ sid $=3671216$ ), hosted by the Scott Library. The Filters page is publically available for anyone to copy and paste.

\section{Strategy 6: Negotiating with faculty to make systematic review search assignments reasonable}

Instructors in various courses across all of the health sciences faculties set systematic reviews as marked assignments. Faculty member sometimes set the assignments without providing instruction in search techniques, they do not clearly articulate the limits of the assignment, or they may not understand the complexity of what they are requiring of the students. The result can be a deluge of consultation requests at the Library. Librarians actively negotiate with instructors to stabilize the demand.
Strategy 7: Requiring clients to do advance preparation for searches

To ensure that researchers arrive better prepared for their search consultation, the Scott Librarians have developed a systematic review protocol form (Appendix A) and a generic search preparation form (Appendix B), which can be sent to researchers in response to a consultation request. The search forms allow the researchers to do some advance planning and flesh out the details of the research question.

\section{Strategy 8: Educating our researchers}

Our researcher education program has a three-pronged approach. First, Scott librarians have supported both a graduate level course in systematic reviews, offered by the School of Public Health, and an Evidence Based Medicine workshop, Putting Evidence into Practice (http://www.pep. ualberta.ca/), offered seven times between 2003 and 2012. Second, Scott librarians maintain a web-page dedicated to systematic review searching (http://guides.library.ualberta. ca/systematicreviews). Third, beginning in January 2012, the Scott Library began offering a three-hour, hands-on "Introduction to Systematic Review Searching" workshop, accredited by the Royal College of Physicians and Surgeons of Canada for continuing medical education credits. Participants are asked to read two articles in advance [16, 17] and set up a citation management account. In the class they receive instruction in and have the opportunity to practice structuring a search, identifying and selecting databases, identifying grey literature, searching one or two databases, exporting references, recording their searches, and preparing the search part of the methods section of a research paper.

\section{Outcomes}

Strategy 1: Freeing librarians' time by ensuring that all work is assigned at the correct level

Freeing librarians' time by reassigning work to nonacademic staff has been an effective strategy. Librarians formerly worked scheduled hours on the reference desk and Saturdays. Staffing the reference desk with public service assistants has allowed librarians more time with fewer interruptions to provide consultation services to researchers.

\section{Strategy 2: Building searcher capacity in the librarian community}

The effectiveness of our initiative to build searcher capacity in the community is unknown. Twenty-one local librarians and 18 students in the School of Library and Information Studies have taken the training. There is no way to track whether or not these colleagues are actively conducting systematic review searches. To maintain competence, librarians need to practice regularly. In subject areas outside of health sciences, the demand is typically not strong enough to keep searchers' skills current. Further, librarians outside of the academic environment may not have a mandate to supply systematic review searching as a part of their service suite. So, although they may have the capacity to perform searches, it may not be part of their work expectations. 


\section{Strategy 3: Lobbying for additional librarian and expert searcher positions}

Lobbying for additional librarian and searcher positions is an ongoing activity. Both academic and government library environments have suffered cutbacks. Several grantfunded research programs associated with the University have been terminated and staff positions, including expert searcher positions, have been lost. However, in local organizations outside of the Library, at least one new position was filled and several were re-appointed. It is difficult to tell if our lobbying efforts have had an effect or if this represents the natural ebb and flow grant-funded academic research projects.

\section{Strategy 4: Redefining service policies for external users}

Redefining service policies to focus only on our internal user populations has removed a user population from the pool that fuels the demand for expert search services. However, health research funders strongly encourage crossinstitutional research projects, and nonacademic health organizations rarely supply access to library services and collections that match those of large academic research libraries. We are aware of several collaborations between researchers in our primary user group and those external to the University, in which the University-based researcher accesses library resources on behalf of the research team.

\section{Strategy 5: Better organizing search support resources}

Improving efficiency by better organizing search support resources has been effective. Being able to quickly find a filter and add it into a search is definitely a time saver. Scott Library has a project under way to create more filters for common searches. Although we have no statistics to track how often filters stored in the Ovid Expert Searches are used, those on the Health Sciences Search Filters guide have been accessed 1213 times between the launch of the page in May 2013 and August 2014.

\section{Strategy 6: Negotiating with faculty to make systematic review search assignments reasonable}

Conversations with instructors have helped mitigate demand. Discussions revealed that for one class, the students were expected to do the assignment without seeking help from Library staff. In another case, the assignment was revised to limit the search to a single database. In a third instance, the subject librarian supplied a web-based search guide tailored to the course, which answered many of the students' questions. Liaison librarians are continuing conversations with faculty whose course assignments include systematic review searching.

\section{Strategy 7: Requiring clients to do advance preparation for searches}

Scott Librarians report that requiring clients to do advance preparation for searches has had several effects. Search forms have been used in more than 75 consultations (September 2013-August 2014). Having received the form, many researchers move their appointment to a later date allowing time to discuss search details with their supervisors or research teams. Librarians report that researchers who have spent time working with the form arrive at the Library better prepared, have a better grasp of the concepts around systematic reviews, and generally require less introductory instruction before the search. However, there are also researchers who do not take the time to engage with the questions on the form. Sometimes researchers have been observed filling out the forms while they wait for their appointment, and then handing them to the librarian as though it were an assignment, rather than using them as a tool to guide thinking about the search.

\section{Strategy 8: Educating our researchers}

Educating researchers has been our most popular and successful Strategy. Since January 2012, the Scott Library has offered the "Introduction to Systematic Review Searching" workshop 25 times, with 338 researchers attending. These frequently fill up within a day or two of being posted, even though there is no formal advertising. This popularity is a double-edged sword. We know that offering the class has actually increased the demand for consultations, because participants inform us that they have made an appointment after having taken the class. One of our librarian colleagues described the courses as effectively "painting targets on our backs." However, these researchers acquire a better understanding of what they need for their search, so they require less consultation time. Because the classes have significant hands-on components and participants are encouraged to bring their research questions, they often get started on their search during the class and then make an appointment to improve it or adapt it to other databases.

The teaching program has definitely raised the profile of the Scott Library with the health sciences faculty. Library administration and the University's research administrative offices are also becoming more aware of systematic reviews as they continue to gain importance worldwide, and expand to disciplines outside of health sciences.

\section{Discussion}

The strong demand for librarians as collaborators on systematic reviews and teachers of systematic review searching is evidence that this work is highly valued and that there is a need for the Library to continue providing the service. It is not clear when, or if, we will reach a peak in the demand for these services. The John W Scott Library's eight-pronged approach to managing the demand for librarian services in systematic review searching will take time to show results. Some initiatives such as educating colleagues and developing new positions for librarians may take years in the best of economic conditions. Others, such as making filters readily available to all searchers, have been fairly easy initiatives to implement. In the short term our efforts save librarians time by having better educated and prepared users, by making class demands for systematic reviews less onerous, and by having search tools such as filters available and easy to locate. Our librarians' time has been better focused by redirecting their reference time from general reference duty to complex searching and by focusing on meeting internal users' needs. Overall, the strategies have allowed us to keep up with service demand, but it will be necessary to continue applying these strategies, adapting them and evaluating them as we go forward. 


\section{References}

1. McKibbon KA. Systematic reviews and librarians. Lib Trends. 2006;55(1):202-15. doi: 10.1353/lib.2006.0049.

2. Bastian H, Glasziou P, Chalmers I. Seventy-five trials and eleven systematic reviews a day: how will we ever keep up? PLoS Med. 2010;7(9):e1000326. doi: 10.1371/journal.pmed. 1000326.s001.

3. The Cochrane Collaboration. Cochrane reviews [Internet]. The Cochrane Collaboration; 2014 [cited Dec 5, 2014]. Available from: http://www.cochrane.org/cochrane-reviews.

4. Cochrane database of systematic reviews: Total cochrane reviews and protocols. $<b r />$ [Internet]. Oxford, England: The Cochrane Collaboration; 2014 [updated May 26, 2014; cited Dec 4, 2014]. Available from: http://www.cochrane. org/cochrane-reviews/cochrane-database-systematic-reviewsnumbers.

5. Harris MR. The librarian's roles in the systematic review process: a case study. $J$ Med Lib Associat. Jan 2005;93(1):81-7.

6. Lasserre K. Expert searching in health librarianship: a literature review to identify international issues and Australian concerns. Health Inf Lib J. Mar 2012;29(1):3-15. doi: 10.1111/j.1471-1842.2011.00974.x.

7. McGowan J, Sampson M. Systematic reviews need systematic searchers. J Med Lib Associat. Jan 2005;93(1):74-80.

8. Rethlefsen ML, Murad MH, Livingston EH. Engaging medical librarians to improve the quality of review articles. JAMA. 2014;312(10):999-1000. doi: 10.1001/jama.2014.9263.

9. Higgins JPT, Green S (editors). The Cochrane handbook for systematic reviews of Interventions. Version 5.1.0 [updated March 2011] The Cochrane Collaboration; 2011.
10. Institute of Medicine of the National Academies. Finding what works in health care: standards for systematic reviews; 2011. http://www.iom.edu/Reports/2011/Finding-What-Works-inHealth-Care-Standards-for-Systematic-Reviews/Standards. aspx.

11. Grimshaw J. A knowledge synthesis chapter. Canadian Institutes for Health Research; 2010 [cited Sep 1, 2014]. http:// www.cihr-irsc.gc.ca/e/documents/knowledge_synthesis_chapter_ e.pdf.

12. Cobus-Kuo LG, Genevieve G, Kloda L. Research synthesis in graduate research: a scoping review/presented at scaling new heights together 38th annual CHLA /ABSC conference, Montreal, CA; 2014.

13. Petticrew M. Systematic reviews in the social sciences: a practical guide. Malden, MA; Oxford: Blackwell Pub; 2006.

14. Campbell S, Chambers T, Chan L, Chatterley T, Chojecki D, Dennett L, et al. Teaching health sciences librarianship with a very large team: breaking the borders of the one instructor model. J Eur Associat Health Inf Lib. 2012;8(3):10.

15. Fyfe T, Dennett L. Building capacity in systematic review searching: a pilot program using virtual mentoring1. J Can Health Lib Associat. 2012;12:12. doi: 10.5596/c2012-009.

16. Hemingway P, Brereton N. What is a systematic review? 2nd ed. London, UK: Hayward Medical Communications; 2009

17. Grant MJ, Booth A. A typology of reviews: an analysis of 14 review types and associated methodologies. Health Inf Lib J. 2009;26:91. doi: 10.1111/j.1471-1842.2009.00848.x.

\section{Appendices}

Appendices A and B appear on the following pages. 


\section{Appendix A: Systematic Review Search protocol form Systematic Review Search Protocol}

Title

Research Team members and contact information

Phone:

Phone:

E-mail

Phone:

E-mail

Phone:

E-mail

E-mail

Introduction (Describe the background to your study)

\section{Objectives}

The objective of this review is to conduct an up-to-date systematic review of

\section{Methods}

Criteria for considering studies for this review

\section{Types of studies}

To be included, studies will be.....

Types of participants (Population)

Studies including.....

Types of interventions

Types of outcome measures 


\section{Primary outcomes}

The primary outcome will be ....

\section{Secondary outcomes}

1.

2.

3.

\section{Search methods for identification of studies}

\section{Electronic searches}

We will identify studies via systematic searches of bibliographic databases including (list databases)

We will search electronic data bases using the following terms

(List likely keywords)

We will/will not limit by date (ist date range)

We will/will not limit by language

We will/will not include unpublished materials

\section{Appendix 5- Search Strategy - Grey Literature}

Grey literature search will be conducted as follows:

We will include

Yes ___ No - Clinical trial registries (Cochrane Central Register of controlled trials, controlledtrials.com and ClinicalTrials.gov) to identify recent and ongoing studies.

Y Yes ___No - Web of Science/Scopus searches of the sentinel paper ${ }^{5}$ from each of the reviews will be completed at the end of the searches to identify any additional potentially relevant studies.

$$
\text { Yes ___ No - Google Scholar web search. }
$$

Yes N_ No - Dissertations and Theses

Yes ___ No - Hand searches of the most recent subject conference abstracts associated with Canadian and research meetings to identify recently completed but not yet published studies. Please list relevant meetings:

Yes ___ No - bibliographies from included studies, known reviews and text for additional citations. 


\section{Does not have to be completed for Search Session Data collection and analysis}

\section{Selection of studies}

How will you define inclusion/exclusion criteria?

Who/how many people will select from the complete title list?

Who/how many people will make the secondary selection?

How will you resolve disagreements?

\section{Data extraction and management}

How will you do your data extraction and management

Assessment of risk of bias in included studies

Quality Assessment (Risk of Bias):

How will you assess risk of bias?

Interpretation of the Results:

\section{References}

List relevant papers that you have already found: 
Appendix B: General Search Preparation Form

John W. Scott Health Science Library

Consultation Preparation

Please bring this completed form to your search consultation. Thanks.

1. Names of Researchers

2. Research Question/Topic in 1 or 2 sentences:

3. Project type (e.g., thesis/dissertation, capping project, RA):

If this is a systematic review, do you need to have a librarian conduct searches and co-author on publications YES NO

4. Timeline (when do you need to have the search completed):

5. Have you consulted library staff about this topic before? YES NO a. With which librarian did you meet?

6. Have you done any initial searches? YES NO

7. In which databases did you search?

8. Search Terms used: 


\section{Things to think about}

1. What type of literature review are you doing?

Not sure? This article describes various review types, provides examples, and identifies the strengths and limitations of each review type:

Grant, M., \& Booth, A. (n.d). A typology of reviews: an analysis of 14 review types and associated methodologies. Health Information And Libraries Journal, $\underline{26(2), 91-108 .}$

2. If you have already found some key resources (e.g., articles, books), bring them along to the consultation.

3. How exhaustively do you want to search? A few key resources vs a comprehensive review?

4. How recent does the info need to be?

5. Must it be published research studies only? Could it be a government report, program description, unpublished thesis or dissertation, conference presentation/proceedings, etc?

6. If you don't find anything, how would you expand your search?

7. Will you need to limit by

- Language?

- Date?

- Geography?

- Ethnic group?

- Age group?

- Type of publication?

- Any other inclusion/exclusion criteria?

8. If you do not have a Refworks account already, you may want to create one to manage your references:

- RefWorks http://guides.library.ualberta.ca/refworks

- Set up a RW account

- If you are working from off-campus, use the Group Code

- When you click on Bibliography, you can choose the citation style you want

- Always proofread your reference list/bibliography to make sure it's correct

- You can download Write N Cite to use with Microsoft Word (From your Refworks account, click on Tools - Write N Cite) 